\title{
Convergence in Tourism and Divergence in Agriculture as a Perspective to Foster Sustainability All Round
}

\author{
Markus Klemens Zaplata1, Lutz Philip Hecker² \\ ${ }^{1}$ Hydrology and Water Resources Management, Brandenburg University of Technology Cottbus-Senftenberg, \\ Siemens-Halske-Ring 10, Cottbus, Germany \\ ${ }^{2}$ Chair of Economics, in Particular Environmental Economics, Brandenburg University of Technology Cottbus-Senftenberg, \\ Erich-Weinert-Straße 1, Cottbus, Germany \\ Email: markus.zaplata@b-tu.de, lutzphilip.hecker@b-tu.de
}

How to cite this paper: Zaplata, M. K., \& Hecker, L. P. (2018). Convergence in Tourism and Divergence in Agriculture as a Perspective to Foster Sustainability All Round. Advances in Applied Sociology, 8, 464-469.

https://doi.org/10.4236/aasoci.2018.85027

Received: April 9, 2018

Accepted: May 18, 2018

Published: May 21, 2018

Copyright $\odot 2018$ by authors and Scientific Research Publishing Inc. This work is licensed under the Creative Commons Attribution International License (CC BY 4.0).

http://creativecommons.org/licenses/by/4.0/

\begin{abstract}
Human endeavours are indebted to become more sustainable and self-sustained. One popular activity (or domain) has huge potential for major progress in sustainability in the short term, namely tourism. When receiving services, tourists interact directly with other humans who reside at their holiday destination, and tourists are typically receptive to their surroundings. This in itself is conducive to flexibility and convergence in the roles of tourism service-providers and recipients. Such a convergence of opportunities equates to individual temporal compensation and permeability within the distribution of roles. That may lead to more equality in people's personal lives, and may be the key feature for tackling social and environmental problems in tourism, and to increasing sustainability. Thus, via convergence, tourism could become more equitable. In global agriculture it is the other way round: via the preservation and enhancement of divergence, agricultural practices could be more appropriately arranged alongside natural habitats, to achieve greater spatial sustainability all round.
\end{abstract}

\section{Keywords}

Fairness Principle, Global Empowerment, Host-Guest Relationship, Temporal versus Spatial Demands, Travel

\section{Introduction}

This opinion piece presents a very intuitive suggestion to foster true sustainability in global tourism. World-wide, employees experience increasing demands at 
work which is associated with high physical and mental stress levels. A common and popular option to alleviate stress is recreation in the form of tourism. Increasingly, destinations chosen for taking a "time out" in form of holidays are in distant parts of the world characterised by pure and untouched nature. Tourism hence involves nowadays more often encounters and exchanges across cultural boundaries and across population groups with radical different financial performances (Scavenius, 2013).

Frequently, the beauty of nature can only be experienced away from extensive technical and/or industrial infrastructures. Although offering pure nature is typically beneficial for generating revenue from tourism, the presence e.g. of a pronounced industry is typically required to turn a region into an economic "success" story. As a consequence, general wage levels tend to be low in untouched nature paradises due to lacking industrial or natural resource depleting economic development.

However, to be sustainable, services provided to tourists by local residents need to generate fair wages which provide a decent living for local residents. Frequently this is not fulfilled as paradoxically the reason for the tourist visits-untouched nature lacking a technical overprint-causes wages to remain below the breadline. To solve this puzzle, we propose a convergent principle in tourism that allows incomes in tourist-related sectors to be raised to sustainable levels, and contributes to more environmental sustainability and protection. Along with this, we propagate greater divergence in agriculture as convergence in tourism in combination with diversity in agricultural land use is the ultimate key to sustainability, in its social and scientific dimensions.

\section{Practical Economics of Tourism: Convergence}

The outcomes of numerous laboratory studies indicate that individuals are not only self-interest guided but also take the well-being of others into consideration (Gürtler \& Gürtler, 2012). Based on empirical evidence, the theory of inequality aversion postulates that economic players dislike unequal payoffs among market participants (Bolton \& Ockenfels, 2000). Accordingly, the disutility resulting from unequal outcomes may give incentives for action or behaviour change in order to close the inequality gap.

A field where the clash of inequality is felt in particular is tourism of prosperous individuals at exotic, nature-based places. The trade-off relation of conserving the beauty of untouched nature and economic development requires the population at touristic destinations with virgin nature to live frequently in fragile economic conditions. As a consequence, poor local residents encounter wealthy tourists who may be even characterized by receiving continued payment of wages or other benefits at home during their time on vacation. They come to use their leisure time for recreational purposes, to receive a good service and to make, in general terms, the most out of their stay.

However, the observation of the flagrant inequality between tourists and the 
local population likely affects negatively this endeavour in some way or another. Decency and benevolence are deciding though subjected to the risk being left behind to the extent that the stay in natural beauty saves visitors even money since financial contributions at home exceed the expenses for the vacation. In consequence, the aim of more economic equity across stakeholder groups should be addressed right out in the open. With a particular focus on individuals with a strong aversion against any interpersonal inequality we suggest therefore the idea to per se spend at least the money amount provided through the continued payment of wages or holiday pay on site in the tourist area. The benefits of this behaviour change could be manifold and may contribute to a new concept of tourism which is more sustainable in economic, social and environmental terms:

Mitigation of global economic imbalance and convergence: To be sustainable in economic terms, tourism has to generate earnings that at least provide subsistence for local residents' working. By increasing spending in visited areas tourists will make a decent remuneration for the consumption of local products and services. If practiced on a large scale, this change in behaviour will help to mitigate global economic imbalances, perceived as inequality in incomes, and foster the convergence of economic living conditions (Doran, 2010). To make this new approach work, tourists are however required to adapt to local standards which possibly includes the willingness to make sacrifices on the quality and quantity of locally supplied goods and services.

Tourism and the environment: Potentially, there are positive side effects on the environment as well. Compared to the current, likely unfair situation, travel expenses are supposed to augment due to the requirement of increased tourist spending on site. Naturally, one expects the number of holiday journeys to decrease in response to an increase in costs. However, in terms of global climate change, a reduction in transportation would provide a welcomed contribution towards the necessary reduction in $\mathrm{CO}_{2}$ and $\mathrm{NO}_{\mathrm{x}}$. Furthermore, the environment at the local level should benefit in cases of extreme poverty as in such situations the direct spending of a small fraction of the tourist income is reasonable due to low reservation wages at poor holiday destinations. Instead, tourists then should support charities working towards waste reduction, environmental education, nature protection, or other sustainable measures at the holiday destination, by making donations to relevant organisations.

Overcoming the disutility of inequality perception: If tourists spend less than the money they have at their disposal through the continued payment of their wages or holiday pay, they would be saving money while doing nothing but travelling and enjoying themselves on holiday. Since individuals sensitive to inequalities perceive the increase in wealth of tourist during their time on holiday as unfair they derive a disutility from its occurrence. Therefore, they should be willing to sacrifice some of their holiday journeys in exchange for the possibility to pay higher remuneration to the local population at the tourist destination. Accordingly, we assume that in terms of recreational benefits and derived utility 
of individuals, the smaller number of holidays will be compensated for by greater satisfaction or mindfulness for the tourists, due to them experiencing (and contributing towards) more fairness and equality.

As a result, if practiced on a large scale, the proposed behavioural change could contribute to a fairer world in which people from more regions would be able to afford holiday travel. Holiday service-providers and holiday service recipients would be less invariant and more convergent (Pope Francis, 2015) as the roles of tourists and local residents would be alternating, rather than exclusive. Since leisure time continues to gain significance it indeed is important for the well-being of our planet and its people that leisure and sustainability become a value pair. Applying our idea of increased tourist spending for stays at distant, exotic and nature-based destinations may contribute to achieve the required balance in living and working conditions for people on the whole. Economically, the system may become more compensatory as it allows more permeability (or, in some sense, the democracy): people work for the benefit of tourists and-during a different time period-are tourists themselves. The principle will lead to convergence in the individual lives of people living in different parts of the world. Theory already suggests that ephemeral exchanges sustain fairness (Henrich et al., 2010); proper tourism might impersonate such exchanges fostering both fairness and sustainability.

\section{Necessary Practice in Large-Scale Agriculture: Divergence}

The convergent principle in tourism aims to be beneficial for people; however, convergence of the environment and landscape at a large scale is not proposed. The growing global human population means that care and vigilance is required to preserve the natural environment and landscape, not least because of their recreational function. Here, to care means to advocate for the maintenance of or, in some places, the enhancement of divergence in agriculture.

Grassland biomes, for instance, suit best to an extensive cereal or grain production in the long run. That is for one simple reason: cereals are grasses, and the soils in grassland are suitable for cereals. The suitability of land for the cultivation of different agricultural products is readily explained by ecological succession which is defined as the directional cumulative change in the plant species that grow in a given area through time (Zaplata et al., 2013). Generally, a succession series starts with bare soil and, via transitory communities, generally leads to biocrust, grassland or forest communities (depending on precipitation demands of the floristic composition).

Depending on the natural conditions in a particular area, farming causes different effects on the environment. In a rain forest site, for instance, farming means that the plant community is moved from a late successional community to an artificial community which resembles an early successional stage. In the course of the transformation from rainforest, the farmed fields will lose a lot of nutrients, which tropical soils do not have in abundance. Thereby the land will 
become useless for farming rapidly. That means the particular features of typical soils yet covered by rainforests impair the practice of intensive, industrial farming (Hirschberger \& Winter, 2018), which started and is still common practice in regions where soils are more resilient to nutrient loss and other unsustainable human activities. Eventually, intensive farming is generally not sustainable in large areas of the world due to the frequent prevalence of less forgiving soil conditions.

Consequently, agricultural practices need to adapt or stay adapted to local conditions in order to be sustainable. This implies divergence of agriculture on a large-scale as each region of the world should ideally produce and supply substantial numbers of crops and fruits which match the states in its ecological succession and its particular biomes. To realize Ricardian comparative advantages (Ricardo, 1817) and make the most of divergence, the agricultural production system should be complemented by fair trade agreements with trade connectivity enabling an internationally reciprocal exchange of goods.

Divergence may take thereby several forms. To feed the growing human population, there is a choice between using land for less intensive agriculture, which is less harmful for the environment but requires a greater area of land. Alternatively, agricultural practices could be more intensive. Higher degrees of intensity require less land and yield more crops per unit land but are more harmful for the environment on site. Ultimately, different patterns and forms of agricultural land use will emerge in different regions and areas in the world depending on the free and informed choice of local populations that take the natural conditions of their homelands into account.

\section{Conclusion}

We suggest fostering convergence in touristic endeavours and divergence in agricultural practices as a measure to create a fairer and more sustainable world. Poor local residents meet wealthy tourists who often receive continued payment of wages or other benefits at home during their time abroad. If financial contributions at home exceed the expenses for the vacation, a stay abroad saves visitors even money. For the sake of fairness, we therefore suggest animating affluent tourists to per se spend at least the money amount provided through the continued payment of wages or holiday pay in the tourist area. This behaviour would help 1) to alleviate poverty and correct economic imbalances in form of less pronounced income inequalities and more convergence, 2) to remedy the disutility the occurrence of inequality causes individuals with an inequality aversion, and 3) to improve environmental conditions through more funding availability for environmental protection. Definitely, higher degrees of convergence in tourism should be complemented by high degrees of divergence in agriculture. The multidimensionality of environmental conditions across the world requires sustainable agricultural practices adapted to local settings producing thereby manifold patterns of agricultural land use. If convergence is applied in tourism 
alongside divergence in agriculture, this may lead to an ideal future situation where every human will be a tourist at times visiting thereby diverse landscapes in different regions of the world which are not unanimously characterized by an omnipotent presence of maize and soy fields. The widely travelled tourist can experience aspect changes, not only in the natural landscape, but to some degrees also in the cultivated landscape. Noticing changes can foster a feeling ideal for journeys, namely the feeling of being on a journey, while travelling through a planet equipped with great diversity! Besides, this is a way to approach the saying "a change is as good as a rest". The benefits that tourists can receive from that diversity, and its genuine accessibility, mean that tourists are respected guests everywhere on the planet.

\section{References}

Bolton, G. E., \& Ockenfels, A. (2000). ERC-A Theory of Equity, Reciprocity, and Competition. American Economic Review, 90, 166-193. https://doi.org/10.1257/aer.90.1.166

Doran, C. J. (2010). Fair Trade Consumption: In Support of the Out-Group. Journal of Business Ethics, 95, 527-541. https://doi.org/10.1007/s10551-010-0437-x

Gürtler, M., \& Gürtler, O. (2012). Inequality Aversion and Externalities. Journal of Economic Behavior \& Organization, 84, 111-117. https://doi.org/10.1016/j.jebo.2012.08.007

Henrich, J., Ensminger, J., McElreath, R., Barr, A., Barrett, C., Bolyanatz, A., Cardenas J. C., Gurven, M., Gwako, E., Henrich, N., Lesorogol, C., Marlowe, F., Tracer, D., \& Ziker, J. (2010). Markets, Religion, Community Size, and the Evolution of Fairness and Punishment. Science, 327, 1480-1484. https://doi.org/10.1126/science.1182238

Hirschberger, P., \& Winter, S. (2018). Die schwindenden Wälder der Welt-Zustand, Trends und Lösungswege. WWF-Waldbericht 2018. http://www.wwf.de/fileadmin/fm-wwf/Publikationen-PDF/WWF-Waldbericht-2018.p df

Pope Francis (2015). Laudato si': On Care for Our Common Home. Vatican: Vatican Press.

Ricardo, D. (1817). The Principles of Political Economy and Taxation. London: John Murray.

Scavenius, T. (2013). National Responsibility and Global Poverty. Global Society, 27, 7-23. https://doi.org/10.1080/13600826.2012.734283

Zaplata, M. K., Winter, S., Fischer, A., Kollmann, J., \& Ulrich, W. (2013). Species-Driven Phases and Increasing Structure in Early-Successional Plant Communities. The American Naturalist, 181, E17-E27. https://doi.org/10.1086/668571 